6-1992

\title{
Ten Lessons About Regulation and Schooling
}

University of Pennsylvania

Follow this and additional works at: https://repository.upenn.edu/cpre_policybriefs

Part of the Educational Administration and Supervision Commons, Educational Leadership Commons, and the Education Policy Commons

\section{Recommended Citation}

University of Pennsylvania. (1992). Ten Lessons About Regulation and Schooling. CPRE Policy Briefs.

Retrieved from https://repository.upenn.edu/cpre_policybriefs/48

This document was authored by the Consortium for Policy Research in Education, but no individual authors were identified.

View on the CPRE website.

This paper is posted at ScholarlyCommons. https://repository.upenn.edu/cpre_policybriefs/48

For more information, please contact repository@pobox.upenn.edu. 


\title{
Ten Lessons About Regulation and Schooling
}

\author{
Abstract \\ For the past several years, researchers at the Consortium for Policy Research in Education (CPRE) have \\ been examining state regulation of districts and schools. This policy brief summarizes the highlights of \\ CPRE's analyses and research. It is based primarily on four state case studies of different approaches to \\ regulatory treatment. It also draws from other research on state policy and state-local relations. \\ Disciplines \\ Educational Administration and Supervision | Educational Leadership | Education Policy

\section{Comments} \\ This document was authored by the Consortium for Policy Research in Education, but no individual \\ authors were identified. \\ View on the CPRE website.
}




\section{Ten Lessons About Regulation and Schooling}

State regulation of schooling is coming under increasing scrutiny, primarily for three reasons. First, over the last 10 years state regulation has expanded into a number of areas previously left to local policymakers and educators, leading to increased complaints about the constraining nature of state rules.

Second, policymakers and educators at all levels of government are questioning the types of state regulation, examining the degree to which it should focus on school resources, school practice, or school outcomes. Third, states have been employing extreme variations of regulatory treatment - specifically deregulation and state takeover - in new attempts to respond to diversity among districts and schools. Each of these factors means that regulation has become an increasingly important topic in educational policy and governance discussions.

Local complaints about state regulation have grown over the last decade as more aspects of schooling have come under state purview. For example, whereas most states delegated teacher salary decisions to districts prior to the mid $1980 \mathrm{~s}$, by 1986 , at least 30 states had set minimal salaries (Darling-Hammond and Berry 1988). Similarly, states entered into the area of curriculum in an unprecedented fashion, making policy about required courses, time spent on various subjects, and skills to be tested (McDonnell and Fuhrman 1985; Fuhrman, Clune and Elmore 1988).

The growing volume of regulation has led to renewed fears about the loss of local control and to more critical examination of the types of regulation.

State education regulation can be classified into three types, depending on whether the focus is school inputs, school processes, or school outputs. The input category includes requirements about resources, such as rules about certain levels of expenditure or necessary teacher qualifications. School process regulations concern the organization and delivery of instruction. They set parameters for school practice by specifying the subjects to be offered, class sizes or grade-level organization. Regulations that focus on outputs or outcomes set levels of student performance or school completion, for example.

Traditionally, regulation has focused on inputs and processes because consensus about outcomes has been lacking (Smith and O'Day 1991). However, increased state regulation of process over the last 10 years and research evidence suggesting that schools need more flexibility about the way they organize and deliver instruction (Purkey and Smith 1983), have led to growing criticism of process regulation.

Dissatisfaction over the growth of regulation is encouraging state policymakers to experiment with new forms of regulatory treatment. Several states exempt some schools and districts from certain regulations while they focus more oversight on those that have had problems complying with state rule. Efforts to differentiate regulatory treatment in turn raise questions about the purposes and effects of state education regulation, contributing to the current debate.

For the past several years, researchers at the Consortium for Policy Research in Education (CPRE) have been examining state regulation of districts and schools. This policy brief summarizes the highlights of CPRE's analyses and research. It is based primarily on four state case studies of different approaches to regulatory treatment (see publication list, p. 9). It also draws from other research on state policy and state-local relations.

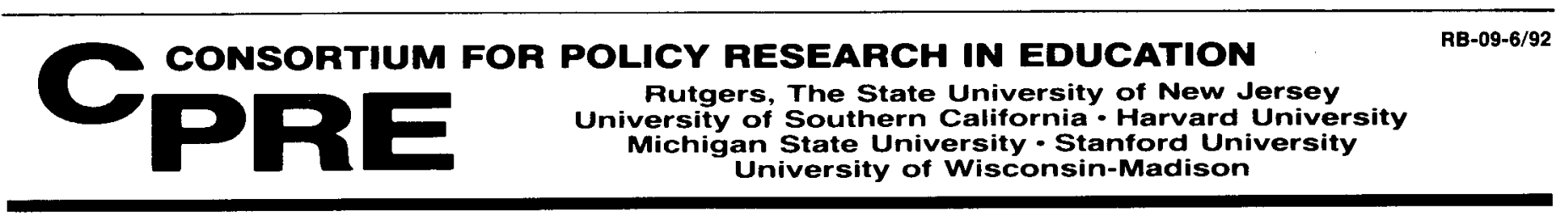




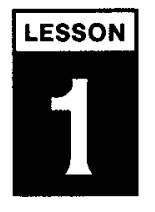

The term "regulation" takes on a number of meanings in discussions of education governance. Lack of clarity about the nature and source of external restrictions hinders discussions about the relationship between regulation and constraints on practice.

Policymaker and educator references to education regulation frequently encompass a variety of governmental policies, including but not limited to regulation. The term is used to refer to policies that set standards, be they laws or statutes, rules with the force of law, or guidelines that are in fact voluntary. Only sometimes is the term regulation applied literally to rules established, generally by state boards of education, to implement statute.

The confusion about regulation is not merely semantic. Often, efforts by states to deregulate apply only to regulation and not to statute.

Sometimes specific statutory provisions are designated as waivable. However, many recent deregulatory programs, whether legislatively sanctioned or not, involve the discretion of state boards and education agencies over their own rules. Legislatures are reluctant to grant boards similar authority over the application of statute.

Ironically, as legislatures become more active education policy leaders, more policy which may have been subject to regulation in the past is now incorporated in statute. Deregulatory efforts may disappoint those expecting most state policy to be subject to waiver or elimination when in fact only literal regulation is at issue.

Another consequence of the ambiguity surrounding the term regulation is the inability of educators to identify the governmental source of constraints on practice. "Regulation" is used by local educators to refer to federal, state and local policy as well as to the interpretation of federal policy by states and 2 the interpretation of federal and

re'gu'la•tion $\backslash, n$ 1: the act of being regulated 2 a: an authoritative rule dealing with details or procedure b: a rule or order having the force of law

stat ${ }^{-} u t e \backslash, n$ 1: a law enacted by the legislative branch of a government.

\section{Source: Webster's Ninth New Collegiate Dictionary} (Merriam-Webster, 1987).

state policy by districts. As a result, complaints about policy barriers are frequently inaccurate; educators identify barriers that are not in fact rule-based or cast the wrong government in the role of regulator. Sometimes the complainants lose credibility in the process.

The effect of the ambiguity may be to misstate the constraints imposed by regulation and to pin too much hope on the potential of deregulation as a strategy to encourage school innovation. Policy discussions of deregulation would benefit from precision and clarity. In considering deregulation as means of enhancing school flexibility, policymakers should assess the contribution of each of the following to creating constraints on practice: statute, rule, guidelines, policies and interpretation of these instruments by local educators and policymakers.

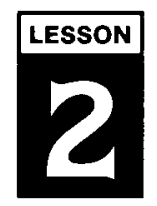

The relationship between regulation and school improvement is uncertain.

Purportedly, regulations mandate activities, processes or behaviors that are related to policymaker notions of good schooling. For example, policymakers regulate class size because they believe smaller classes are better than larger classes. However, the relationship between regulation and good practice is likely to be weak for at least five reasons.

First, like most activities involving judgment and discretion, school practice is not easily amenable to regulation. Regulation is one of many influences on practice, which is shaped by needs, capacities, dispositions, motivations and a host of other factors. Some important aspects of practice with clear links to student learning - such as the presence of explicit instructional school goals - are particularly difficult to regulate. Regulations can call for goals to be developed and specify the process of development, but they can not assure that the goals will be meaningful, consensual, or motivating.

Second, most regulations are likely to be set at minimal levels, providing a floor not a goal for practice or performance. High, or leading edge, requirements mean that for some period of time, and perhaps a lengthy period, most schools in a state would be below standard. This situation is typically viewed as politically intolerable. High standards are likely to be countered by local requests for more resources. Also, the imperative for policymakers has been to do something about the schools and districts at the bottom of the scale that can make the state look bad in comparison to others. Only recently have concerns about national competitiveness suggested that the entire distribution needs to be moved up several notches.

Third, the political factors that promote a focus on the minimal or the lowest common denominator standard are, ironically, reinforced by the findings of educational research that school improvement is a unique, site-based endeavor. Reasoning that excellence cannot be mandated, educators have urged policymakers to minimize requirements. So political consensus can be 
built most easily around those mandates likely to be viewed as least intrusive; one way to minimize intrusion is to construct mandates that are already exceeded by most schools and districts.

Fourth, good practice is difficult to measure. Regulatory enforcement tends to center on measurable proxies of good practice, such as paper trails indicating that good planning processes are followed or that curriculum development is undertaken periodically. The proxies get translated into standard operating procedures, and, over time, the relationship between the goals of regulation and the routines followed can become increasingly weakened.

The lack of fit between the goals of regulation and what regulators can measure leads to a situation that has been termed "regulatory unreasonableness," characterized by formalistic, legalistic, standardized inspection processes, and frequently -severe paperwork burdens (Bardach and Kagan 1982; Bardach 1986; Kagan 1986).

Fifth, the capacity of state regulators to detect non-compliance varies. No state agency has ever been sufficiently staffed to permit lengthy, frequent site visits. Hence compliance typically is assessed through data reports, self-reports by districts, and brief, periodic visits by regulators. Agencies and districts alike struggle with the questions of how adequately paper reports portray school activities and the kinds and extent of evidence regulators can garner in their brief visits to verify the accuracy of reports. Not only are standards likely to be minimal, but efforts to verify conformance to the standards are also likely to be minimal.

Policymakers should consider the degree to which mandates set low sights for practice. While not intending to, policymakers frequently design policy with the most difficult, recalcitrant or poorly performing districts in mind. Policymakers should realize that the resulting standards may be irrelevant or irritating to the vast majority of schools and therefore incapable of stimulating improvement. Alternatives include higher standards and/ or standards that set not only minimums but also growth targets for those above minimal levels. Further, it would be advantageous for states to aim for better matches between regulations and enforcement capacity.

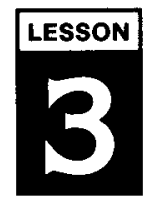

Because regulation is hard to relate to good practice and difficult to enforce, many policymakers are considering ways to focus standards around outcome expectations and to limit regulations about process.

The current interest in deregulation stems in large measure from a belief that regulation of school practice has failed to assure good schooling. Some indict the regulations themselves for stifling school creativity. Others counter that much regulation is non-intrusive and that regulation cannot take the rap for poor test scores in the face of increasing poverty and other deteriorating social conditions. But neither group would assert that the remedy for poor performance is more rules about practice.

However, rules about school practice - about course offerings, the adequacy of facilities, the assignment of teachers in field - have been the prime means of stating policymaker beliefs about adequate service provision. Also, in applying regulations to all, policymakers have attempted to assure minimally equitable schooling. If regulations are to go by the wayside, some other means of holding schools accountable on adequacy and equity grounds must be found.

Policymakers are proposing to substitute outcome standards for process regulation, partly as a result of charges that process regulation constrains necessary school flexibility.

Some reformers argue that schools should make most decisions about specific curricula, the organization of instruction, and pedagogy. They say that districts should focus on coordination and facilitation of school-level decisions rather than rule making. Further, they say, the state's role is to determine and support ambitious outcome goals, not to regulate practice (NGA 1990; Business Roundtable 1990; Smith and O'Day 1991). At the same time, debate rages about whether instructional leadership might come from the national level.

The extent to which relying more on outcome standards will actually lead to less process regulation remains unclear. On the one hand, it had better do so. It would seem counter-productive to layer ambitious outcome expectations on the system without granting schools maximum flexibility in reaching those outcomes so they can tailor programs to the needs of their students. However, the American political tradition has been to add new structures, institutions and rules without subtracting the old (see, for example, Morone 1990).

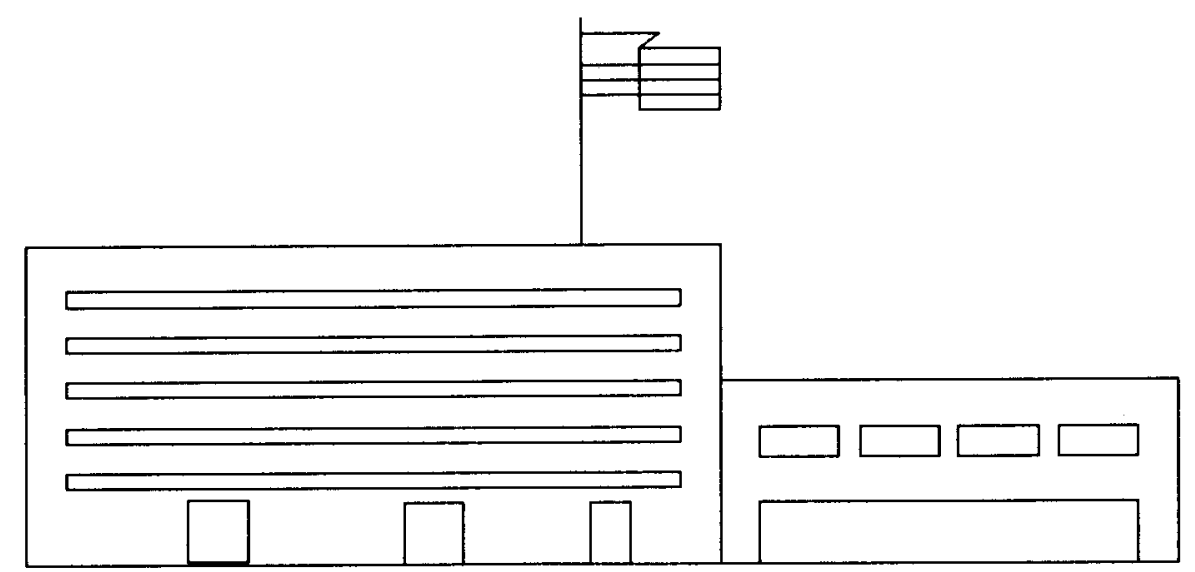




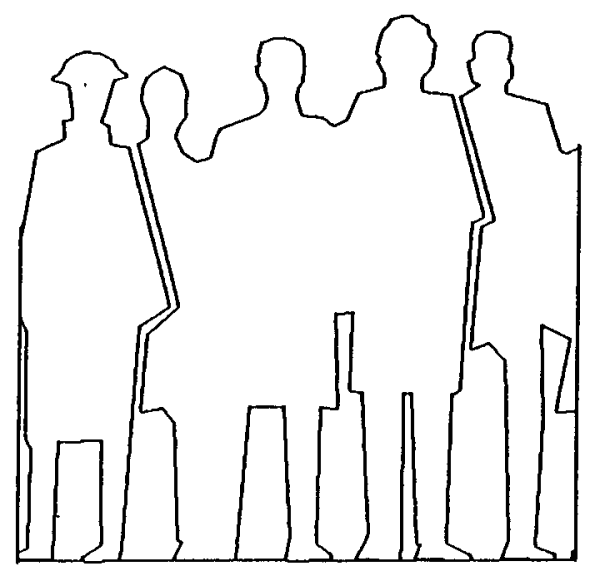

Some process regulations are likely to remain. Adequate levels of health, safety, physical plant maintenance, and financial accountability must be assured. Categorical programs, which typically include requirements to assure that services are targeted to meet special needs, are an important continuing source of regulation. In fact, many practitioners in deregulated schools find their flexibility hampered by special program rules - or the interpretation of those rules - that are not included in the deregulation effort.

For example, while class size limits are lifted in the basic program for deregulated schools in South Carolina, they remain in effect in the state-mandated gifted and talented program. Categorical programs might also be reviewed to focus more on outcomes and less on the regulation of service provision.

Furthermore, it is incumbent on the system to assure that all students have an opportunity to meet new outcome standards, to learn the expected content and skills. Assuring equitable access to wellqualified teachers, high-quality instructional materials, and various instructional offerings may require some degree of regulation. Many argue that opportunity to learn can be measured or tracked without setting standards or constraining practice. Others assert that some regulation of practice is essential for at least some districts, particularly in instances where taxpayer support needs extra leverage or where

4 corrupt practices exist.
If policymakers develop challenging outcome goals and support them with related policies on assessment, instructional materials, and teacher professional development, they will create new structures for accountability (CPRE 1991). This is already happening in a number of states.

Districts and schools can be held responsible for student performance on the outcomes, and regulation of practice will no longer form the cornerstone of state-local relations. Policymakers can then strip away regulations that are no longer necessary and permit schools maximum flexibility in reaching the outcome expectations. Policymakers interested in outcome accountability should make the review and streamlining of regulation, including rules for special programs, an important component of their reform activities.

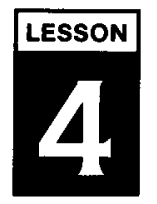

Tying deregulation to high performance seems plausible, but may have perverse consequences.

If accountability were to hinge more on outcome expectations, why not leave process regulation in place only for those not meeting the expectations? Higher achieving schools and districts would be exempted from process regulation as long as they exceeded standards.

If some schools and districts were exempted from regulation, they would not need to be inspected on those regulations. Regulators could devote more time to those who remain regulated. Paperwork could be limited for those exempt and better verified for the non-exempt. Not everyone would have to comply with minimal standards many feel are inappropriate, perhaps constraining and at least not worth the trouble of documenting.

Even though outcome-based accountability is just developing as a strategy, a number of states currently use deregulation, or eligi- bility for waivers, as a reward for higher-achieving and/or consistently highly accredited schools. However, school improvement research teaches that autonomy or flexibility is a likely precursor to improvement. Hence, a logical dilemma is presented: if discretion helps schools improve, why deny it to those who need to improve?

Less successful schools might be the very ones who need aspects of deregulation; unlike highly achieving schools, they have not flourished under the prevailing rules. For most schools that are ineligible if deregulation is viewed as a reward, lowerperformance is not for lack of effort or desire. Let us assume the truly "bad apples," those who deliberately shirk compliance, could be weeded out. The remaining willing, but not yet successful, schools might use flexibility to better meet the spirit of state regulations while not precisely conforming to the letter.

If deregulation is seen as a means of providing schools sufficient flexibility to improve, policymakers should consider the broad range of schools needing improvement. Most schools, the persistent compliance shirkers or "bad apples" aside, could probably benefit from flexibility. Deregulation should not be reserved for the most successful.

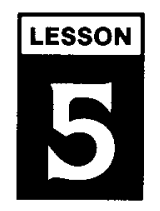

Policymakers are reluctant to remove regulation for persistently troubled districts and schools. Instead, such districts may be subject to enhanced enforcement of regulation through state takeover. However, takeover programs may not solve the troubles and must be carefully designed.

What to do about the "bad apples" is a recurring state policy dilemma. In virtually every state, there are some schools and districts where both achievement and compliance are perpetual problems. Whether political interference or lack of competence is an issue, a heavy state hand is judged to be necessary to 
assure that students are provided minimal services.

Two key decisions arise in designing sanctions for troubled districts. The first concerns the circumstances that warrant punishment as opposed to assistance - are local officials resistant to improvement or are they suffering from lack of capacity or resources?

A logical approach, one which exists on paper in most states, would rely first on assistance and then resort to sanctions only when localities refuse or fail to avail themselves of assistance. However, in practice the sequence of assistance and sanctions can be blurred. Most states lack adequate capacity for assistance, having focused increasingly scarce agency resources on compliance as special programs and attendant regulations have multiplied.

Many states rely on the same officials to monitor and assist which confuses their roles. In fact, it is frequently hard for local officials to discern whether assistance prior to sanctions is meant to forestall sanctions or to gather evidence to justify their eventual imposition.

The second decision concerns the nature of the sanctions. The severest sanction currently applied to substandard districts is state takeover. While takeover programs may act as a deterrent to troubled districts, as currently designed they do little to improve schooling in districts subject to intervention.

CPRE conducted research in Kentucky, focusing on the educational deficiency program that operated until the 1991 Kentucky Education Reform Act, and in New Jersey focusing on the state's intervention in the Jersey City school. The research suggests several problems with takeover programs. First, educational issues at the school may not take priority. Because attention is frequently focused at the central office, where new leadership or state intervenors focus on revising policies and procedures, state efforts to encourage good practices may not filter down to the schools.

Although participating districts may have clear problems related to central management, the teachers, parents and citizens who are suffering through the public stigma of takeover look for solutions to the educational problems that contributed to the sanctions. They may loose both patience and hope if school-level improvement is not a top priority.

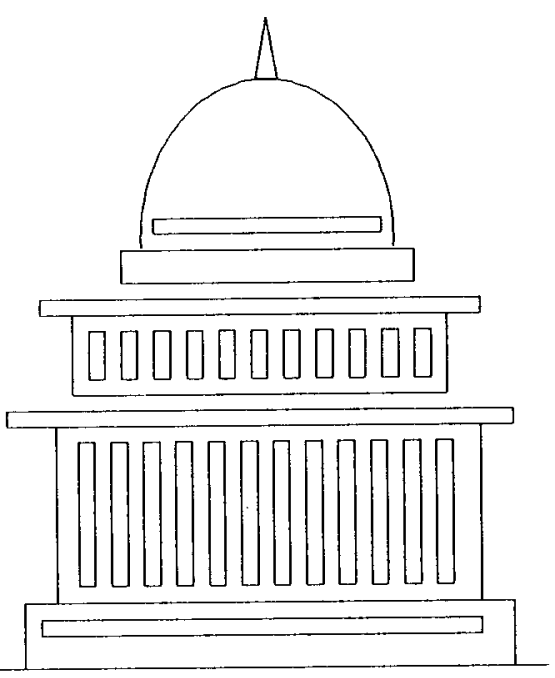

Another concern is that takeover programs are likely to be immersed in a web of documentation, litigation and justification concerning the propriety of the decision, the employment rights of personnel and other issues.

Even assuming that court decisions in the first rounds of takeover would settle a number of matters once and for all, it appears that receivership is so charged and delicate an issue that record-keeping to justify and document every action might take precedence over assisting districts and schools to comply with state standards. Endless documentation is in some ways the essence of unreasonable oversight, even when it occurs in localities clearly requiring oversight.

Finally, takeover programs may not remedy the political problems that can make troubled districts takeover targets to begin with. If previous leadership remains in place, little faith can be placed in the endurance of state-designed management or accountability procedures once state officials leave. If top leadership is removed but virtually all other personnel, including the friends and relatives of the ousted officials, retain tenure rights in the system the potential exists for renewed political interference once the state departs.

Attention to general board and administrator ethics - for example, through training programs - may have more potential than timelimited state intervention in addressing corruption and patronage problems in troubled districts.

Observation of state intervention efforts suggests that policies designed for the handful of schools and districts that would not, absent state direction, provide adequate services, should emphasize assistance. Such a strategy may require enhanced capacity in the state agency or the creation of new sources of help through regional units, universities, peers from other districts and the like. Intervention quickly becomes a focus of litigation and justification which may complicate or blunt state efforts to help. If intervention is necessary, a schoollevel focus would serve educational goals better than a district focus. Political interference may not disappear as a result of time-limited state intervention and may require more general policy solutions.

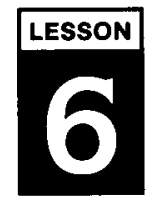

Regulation is often not the barrier it seems.

Although regulation may be only weakly related to good practice, it is wrong to assume that removing regulation will necessarily inspire good practice. If schools are not achieving, or not exemplifying good practice, it is unlikely that simply removing regulation will provide the remedy.

In many cases, regulation is not even the source of policy constraints; local interpretation is frequently mistaken for regulation. Sometimes local leaders fear 5 
zealous monitors and overcomply to be on the safe side. Sometimes they find regulations helpful in garnering taxpayer support or justifying programmatic initiatives. Saying "the state makes me do it," even when that is not literally true, can be useful in persuading citizens, parents and staff to support district initiatives. Also, given the low enforcement capacity of many states, schools that want to break free of regulatory constraints can often find ways of doing so, of creatively non-complying, without formal deregulation.

Even where both regulation and enforcement are real, they are most likely not the primary barriers to good schooling. Tradition probably stifles creativity just as much as regulation; the focus of many aspects of the system - for example, assessments and textbooks - on low-level skills limits the horizon and undermines innovation.

Local lack of interest in many state offers to waive rules supports the idea that regulation is not the only impediment to change. State policymakers tend to view initial low numbers of waiver applications as temporary. They assume that as schools restructure or change - get "vision" - they will find regulation to be more of an impediment. However, in the absence of other factors that promote change - such as technical assistance, models of good practice and high expectations - it is unlikely that schools will change enough to make regulations feel restrictive.

In South Carolina, a highly regulated state, about half the activities undertaken by deregulated schools would have been possible previous to the enactment of reforms that waived rules for certain schools (Fry, Fuhrman \& Elmore, 1992). While deregulation may help spur innovation, as the next section discusses, the regulations themselves are not necessarily in the way.

Dramatic school change should not be expected in the wake of deregula6 tion. Some critics of our over- bureaucratized system assume that simply removing constraints will be sufficient to stimulate school creativity. Policymakers should be aware that the evidence does not support this conclusion.

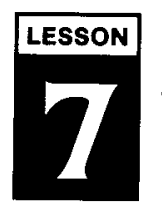

Even though regulation is frequently not a serious hindrance to good practice, under certain conditions, deregulation helps stimulate school improvement.

Once they were deregulated, about two-thirds of eligible South Carolina schools undertook activities, such as integrating curricula and creating opportunities for sustained contact between teachers and students, that seem promising, at least in their initial phases. Although half of these activities would have been possible without deregulation, over 70 percent of the activities were in fact undertaken only after deregulation. Why? What is it about deregulation that influences innovation?

In South Carolina and Washington, deregulatory efforts provide two types of stimulus to change. First, schools that participate in these programs feel that they are expected to innovate as a result and feel some pressure to break beyond existing barriers in the process. The spotlight is on them, at least in the early stages of such programs, to show that they have vision and are not willing to let rules impede. Whether or not they actually do innovate in meaningful ways will only become apparent over time, but at least initially, schools feel a responsibility to examine their programs and identify improvements.

Second, the regulatory flexibility provisions encourage schools to identify, and perhaps act on, the real impediments they face. The process clarifies the extent to which regulation, as opposed to tradition or local interpretation of regulation, is constraining. It also helps to surface other barriers, such as lack of funding or skepticism of schools that may well receive students from innovative schools. Deregulation may remove one excuse for maintaining the status quo and contribute to overcoming other excuses.

A variety of factors interact with deregulatory efforts and affect school-level activity. For example, in Washington additional teacher time is supported in schools participating in the state's Schools for the 21 st Century program. South Carolina funds a university consortium to provide technical assistance to its deregulated schools. In both states schools receive publicity and recognition associated with their special status.

The local district also plays an important intermediary role. In South Carolina, where individual eligible schools are deregulated by the state, ambitious activities are more likely to occur where districts are strongly supportive. Some districts urge schools to take advantage of their status. Some provide leadership and assistance to support innovation. Also, the central office may influence how school personnel calculate risks associated with ambitious change. Since the schools qualifying for deregulation are the most successful in the state, winning both substantial monetary awards and recognition for student achievement, they might fear changes that "rock the boat." Districts can provide support for change that counteracts the possibility of losing recognition and reward dollars.

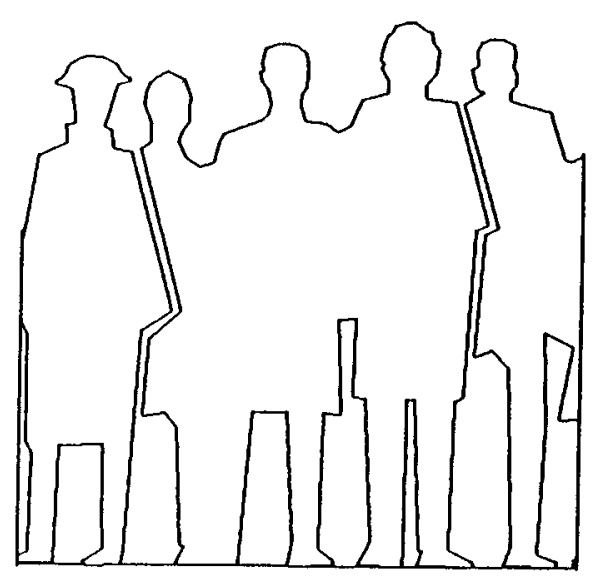


Policymakers can expect deregulation to create expectations for change and to clarify barriers. In that way, deregulation may provide a stimulus for change, but policymakers should also be prepared to offer additional support for change through leadership, assistance, support of teacher planning time and the like.

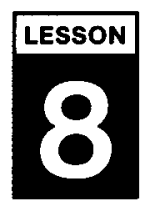

Deregulation will be difficult to achieve through rule-by-rule waiver offers.

The stimulus provided by deregulation is unlikely to come through programs that exempt schools from individual rules upon their request. Individual regulations are less likely to impede than the intersection of regulation. For example, a high school's organization of instruction is shaped by the interaction of regulations on course offerings, graduation requirements, teacher certification and facility use, as well as by nonregulatory factors like college admissions policies. No one regulation operates independently of the others.

Also, if deregulatory programs operate more to spur creative thinking and to clarify boundaries than to remove serious barriers, a single rule request program falls short. Depending on the school to first plan change and then identify regulatory barriers offers a weak stimulus: the barriers remain in planners' mindsets during the development period, the removal of regulation is contemplated only once the change is planned, and a process of state review and approval still must be faced. It is not hard to imagine how such a process may dampen ambition.

Washington's experience with its rule-by-rule request program provides some evidence to indicate that single rule waivers on request programs do not generate much interest. Although the state's Schools for the 21 st Century program of support for restructuring has generated hundreds of applications, few

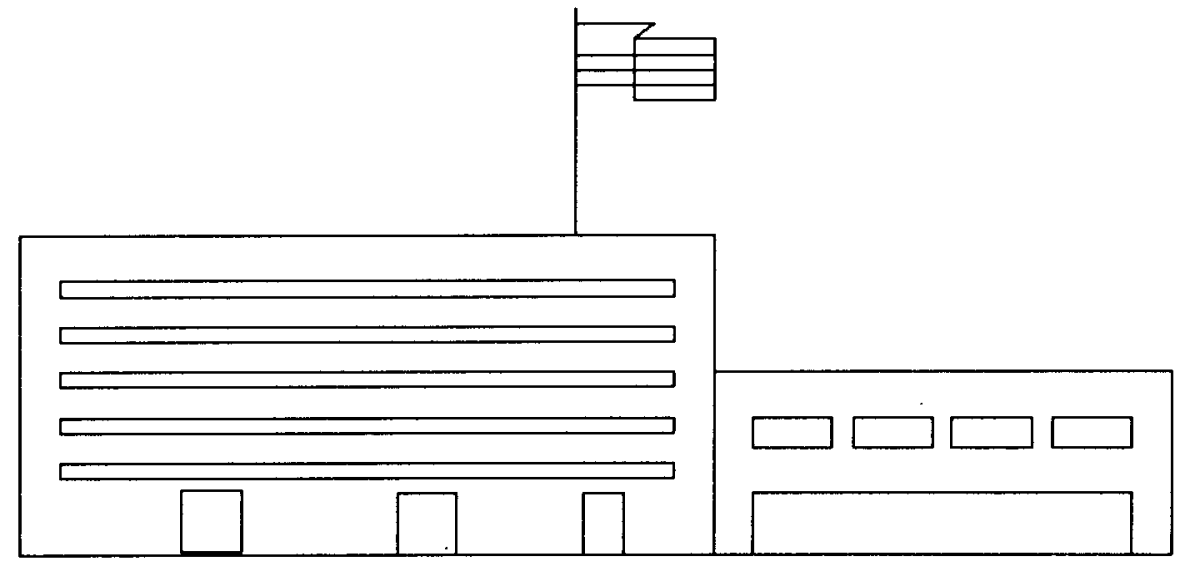

projects have requested waivers for their programs. Of the 21 initial grantees, only 6 requested a total of 15 waivers from state regulation, 9 of which were granted. Eleven of the 33 projects participating as of 1991 were granted waivers in one or more of 13 categories. The most common concerned regulations governing total program-hour offerings for basic skills and work skills (5 projects); and classroom teacher student contact hours ( 5 projects).

A realistic view of the benefits of deregulation - which sees it as a likely but insufficient stimulus for school improvement - sets appropriate limits on expectations from deregulatory strategies. However, even such limited expectations may not be realized through deregulatory programs that depend on waivers of single rules upon request.

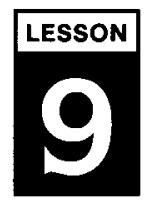

Blanket deregulation appears more promising than rule-by-rule waivers on request.

Granting up front, automatic exemption to regulation may create a more fertile climate for consideration of improvement efforts than rule-by-rule waiver request programs. The reason may be as mundane as the fact that automatic exemption requires no paperwork/ approval process.

But there may be more substantive reasons. Automatic, sweeping deregulation may be more stimulative of change because it broadens the horizon for planning of change, removing parameters more thoroughly than waiver request programs. One might imagine that a very different change process occurs when one is told that a set of rules no longer applies than when one is told to plan an innovation and request exemption from the specific barriers identified. In addition, a blanket exemption from a set of related rules addresses the constraints created by the interaction of regulation.

In South Carolina, both rule-byrule and blanket exemption programs exist. The comparison favors the blanket approach. In 1989, the state enacted Target 2000 reform legislation that included the Flexibility Through Deregulation program. Schools that are taking advantage of blanket waivers under the flexibility program could have removed at least some of the same barriers by applying for individual experimental exemptions before the program existed. Few did, yet most are undertaking activities now that they associate specifically with the advent of deregulation.

Also, few South Carolina schools have applied for waivers through two rule-by-rule programs also created by Target 2000 . Over the first two years of the School Innovation Grant program, 71 schools were funded for implementation of innovations; only 4 of those included waivers. In the Dropout Prevention Grant program which supported 32 grants over the initial two years, there were approximately 15 waivers, many to the same site. 


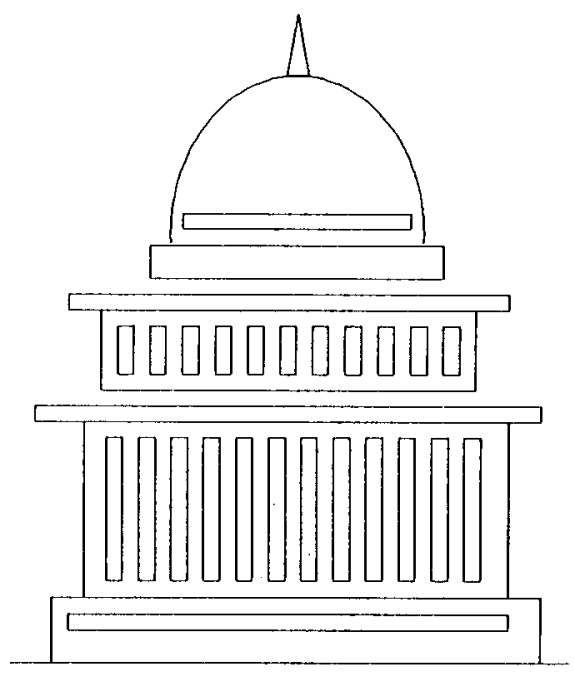

The design of deregulatory approaches is an important influence on their use by schools. As argued previously, deregulation efforts should be designed so as to broaden, not limit, eligibility. Two other design aspects should be noted. First, regulatory exemption should be automatic and not depend on school or district identification and request. Second, many intersecting rules should be eliminated simultaneously.

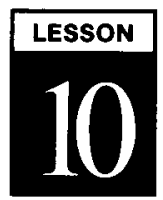

Deregulation is best pursued in combination with an overall state strategy to improve schools.

Deregulation offers the most potential as part of an overall state plan for improving education. That plan should shift accountability away from compliance with process regulations and towards performance on outcomes. State determination of the goals it wishes to achieve and orchestration of various policy instruments around those goals should be the foundation of the plan (Smith and O'Day 1991; CPRE 1991). Deregulation is a strategy for giving schools enough flexibility to meet the goals, not a substitute for clear goals and appropriate policy mechanisms. For example, unless states determine how process dereg8 ulation might help various types of schools better meet state goals, they will likely restrict programs so few schools benefit and the most needy are ineligible.

In the context of outcome accountability, deregulation should include a broad range of schools, not just the highest performing, and provide automatic and blanket exemption. Such deregulation can realistically be expected to provide a stimulus for change but will not, in and of itself, turn tradition-bound schools into exemplars of creativity.
States should consider a range of policies - such as teacher professional development and assistance to schools - to help schools take advantage of the flexibility and maximize achievement. Finally, the schools and districts too persistently troubled to be deregulated may require intervention that is carefully designed around their specific needs. While not panaceas, new approaches to regulation are worth continued experimentation and study in the context of multi-faceted reform of education.

\section{References}

Bardach, E. 1986. "Educational Paperwork." In School Days: The Legalization and Regulation of Education, edited by D. L. Kirp and D. N. Jensen, 124-44. Philadelphia: Falmer.

Bardach, E., and R. A. Kagan. 1982. Going by the Book: The Problem of Regulatory Unreasonableness. Philadelphia: Temple University Press.

Business Roundtable. 1990. Essential Components of a Successful Education System: The Business Roundtable Education Public Policy Agenda. New York: Author.

Consortium for Policy Research in Education. 1991. "Putting the Pieces Together: System School Reform." CPRE Policy Briefs. New Brunswick, NJ: Author.

Darling-Hammond, L., and B. Berry. (1988). The Evolution of Teacher Policy (Prepared for the Center for Policy Research in Education). Santa Monica: RAND Corp.

Fry, Patricia, Susan H. Fuhrman, and Richard F. Elmore, 1992. South Carolina's Flexibility through Deregulation Program. New Brunswick, NJ: Rutgers University, Consortium for Policy Research in Education.

Kagan, R. A. 1986. "Regulating Schools: The Problem of Regulatory Unreasonableness." In School Days: The Legalization and Regulation of Education, edited by D. L. Kirp and D. N. Jensen, 64-90. Philadelphia: Falmer.

Morone, James A. 1990. The Democratic Wish. New York: Basic Books.

National Governors' Association. 1990. Educating America: State Strategies for Achieving the National Education Goals. Report of the Task Force on Education. Washington, DC: Author.

Purkey, S., and Marshall S. Smith. 1983. "Effective Schools: A Review." Elementary School Journal, 83: 427-452.

Smith, Marshall S., and Jennifer O'Day. 1991. "Systemic School Reform." In The Politics of Curriculum and Testing: 1990 Yearbook of the Politics of Education Association, edited by S. Fuhrman and B. Malen. London and Washington, DC: Falmer Press. 